\title{
Originals
}

\section{The Insulin Response to Glucose Infusion in Gestational Diabetes}

\author{
P. M. Fisher ${ }^{1}$, H. W. Sutherland ${ }^{1}$, and P. D. Bewsher ${ }^{2}$ \\ Departments of ${ }^{1}$ Obstetrics and Gynaecology and ${ }^{2}$ Therapeutics and Clinical Pharmacology, University of Aberdeen, Aberdeen, Scotland
}

Summary. Using a glucose infusion test insulin responses and insulin sensitivities were studied in 15 gestational diabetic women at 36-40 weeks gestation. In all women intravenous glucose tolerance had returned to normal at six weeks postpartum. Twelve women had a repeat glucose infusion test done 7-24 weeks (mean 17 weeks) postpartum. The results were compared with previously evaluated normal non-pregnant and normal pregnant standards and insulin responses below the normal $15^{\text {th }}$ percentile were defined as "low". Twelve women had "low" insulin responses in late pregnancy, and six had "low" insulin responses postpartum. The mean insulin sensitivity index of $1.34 \pm 1.21$ (mean \pm SD) was significantly higher in the gestational diabetic group during pregnancy compared with a control pregnant group at $0.53 \pm 0.21(\mathrm{p}<0.01)$. The findings in this study support the hypothesis that gestational diabetes may arise in women who are unable to achieve adequate insulinogenic compensation to pregnancy. Increased insulin sensitivity in gestational diabetes may be a compensatory mechanism.

Key words: Human pregnancy, gestational diabetes, glucose infusion test, insulin response, insulin sensitivity, human placental lactogen, progesterone, oestradiol 17- $\beta$.

The pathophysiology of gestational diabetes has been related to excessive insulin antagonism by the contrainsulin endocrine factors of pregnancy $[1,2,3]$. Others have postulated that when maternal insulinogenic compensation is inadequate to offset the diminished insulin sensitivity, gestational diabetes may supervene $[4,5]$.

Cerasi and co-workers [6] have presented impressive evidence that one of the primary pancreatic defects predisposing to chemical diabetes may be a selective impairment of $\beta$-cell glucoreceptor sensitivity. A "low" peripheral insulin response may be a manifestation of this defect. We have described previously [7] the application of a glucose infusion test (GIT) to groups of non-diabetic women. Diminished sensitivity to endogenous insulin in normal pregnancy was found compared with the non-pregnant state and this was associated with a greater peripheral insulin response. In the present study using similar infusion tests we have investigated the roles of insulinogenic compensation and insulin resistance in gestational diabetes.

\section{Materials and Methods}

\section{Patient Selection}

Fifteen non-obese ( $<85$ th percentile body weight) [8] gestational diabetic women between 36-40 weeks gestation were recruited. The mean age was $28.0 \pm 4.8$ years and the mean percent ideal body weight using the calculated pre-pregnant weight [9] was $100 \pm 8$.

In each case the gestational diabetic state was defined by an increment index of the $25 \mathrm{~g}$ intravenous glucose tolerance test (IVGTT) [10] below 2.97 during pregnancy, and which had risen to normal $(>2.97)$ at six weeks postpartum [11]. No women had any other illness and non were receiving any drugs prior to the initial tests. Following the GIT in pregnancy five gestational diabetic women received Chlorpropamide $100 \mathrm{mg}$ per day until delivery. The remainder had no metabolic treatment. None had any dietary or drug treatment postpartum, and none was breast feeding at the time of the GIT.

The study was approved by the Hospital Ethical Committee and each patient gave her informed consent.

\section{Procedures}

Each woman had a GIT done during pregnancy 2 to 7 days after the diagnostic IVGTT. Following a postpartum IVGTT at 6 weeks, 12 of the women undertook a repeat GIT between 7 and 24 weeks (mean 17 weeks) postpartum. 


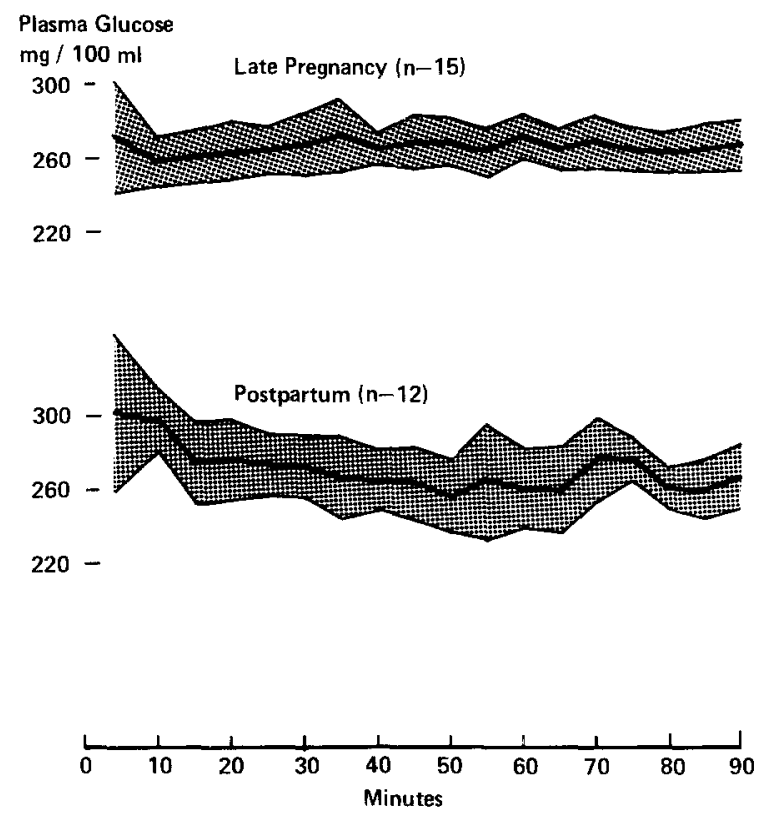

Fig. 1. Plasma glucose levels maintained at infusion in gestational diabetic women during pregnancy and postpartum. Mean (Solid line) \pm SD (Shaded area). The plasma glucose was elevated by an IV loading dose of $400 \mathrm{mg}$ glucose per $\mathrm{kg}$ body weight over $3 \mathrm{~min}$ and maintained by a variable $20 \mathrm{~g} / 100 \mathrm{ml}$ glucose infusion

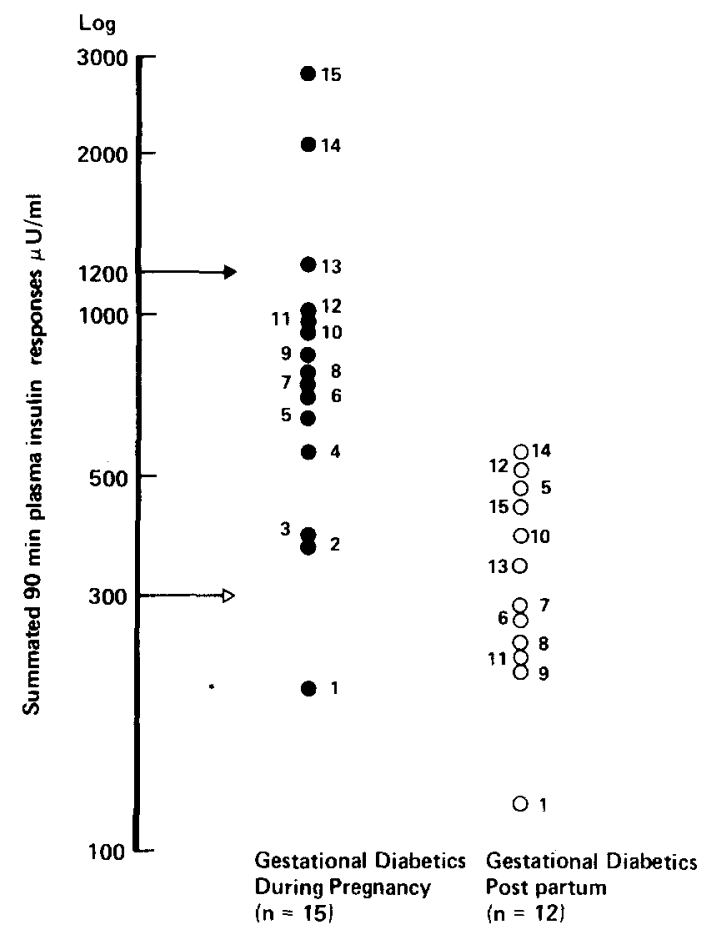

Fig. 3. Summated 90-min peripheral plasma insulin responses in gestational diabetic women during pregnancy $(n=15)$ and postpartum $(n=12)$. The summated insulin response was derived from peripheral plasma insulin responses using circulating insulin half-life values. The cut-off insulin response levels adopted to define "high" and "low" insulin responders are indicated at $1200 \mu \mathrm{U} / \mathrm{ml}$ for pregnant women and $300 \mu \mathrm{U} / \mathrm{ml}$ for non-pregnant women. The numbers indicate the same women

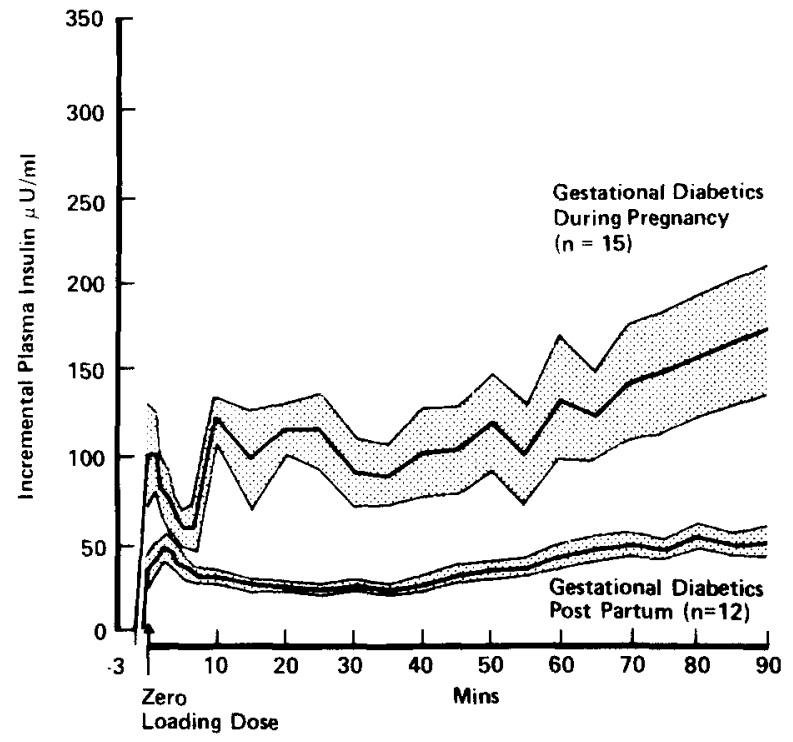

Fig. 2. Biphasic plasma insulin responses in gestational diabetic women during pregnancy and postpartum. Mean (Solid line) \pm SEM (Shaded area). These compound curves include first and second incremental peripheral plasma insulin responses to constant plasma glucose stimuli at $260-270 \mathrm{mg} / 100 \mathrm{ml}$ over the test period

Table 1. Insulin sensitivity indices (mean \pm SD) in chemical gestational diabetic women during pregnancy and postpartum compared with similarly derived values for non-diabetic women [7]

\begin{tabular}{|c|c|c|c|}
\hline \multicolumn{2}{|l|}{$\begin{array}{l}\text { Pregnant } \\
\text { women }\end{array}$} & \multicolumn{2}{|l|}{$\begin{array}{l}\text { Non-pregnant } \\
\text { women }\end{array}$} \\
\hline $\begin{array}{l}\text { Chemical } \\
\text { gestational } \\
\text { diabetics } \\
(\mathrm{n}=15)\end{array}$ & $\begin{array}{l}\text { Normal } \\
(\mathrm{n}=20)\end{array}$ & $\begin{array}{l}\text { Chemical } \\
\text { gestational } \\
\text { diabetics } \\
(\mathrm{n}=12)\end{array}$ & $\begin{array}{l}\text { Normal } \\
(\mathrm{n}=20)\end{array}$ \\
\hline $1.34 \pm 1.21^{\mathrm{a}, \mathrm{b}}$ & $0.53 \pm 0.21^{\mathrm{a}}$ & $3.03 \pm 1.69^{\mathrm{b}, \mathrm{c}}$ & $3.10 \pm 1.67^{c}$ \\
\hline${ }^{\mathrm{a}} \mathrm{p}<0.01$ & ${ }^{\mathrm{b}} \mathrm{p}<0.01$ & ${ }^{c} \mathrm{p}>0.05$ & \\
\hline
\end{tabular}

For the GIT plasma glucose was elevated over $3 \mathrm{~min}$ by a loading dose of $400 \mathrm{mg}$ glucose $/ \mathrm{kg}$ body weight. Thereafter the plasma level was maintained by an adjustable infusion of $20 \mathrm{~g} /$ $100 \mathrm{ml}$ glucose at $260-270 \mathrm{mg} / 100 \mathrm{ml}$. The summated peripheral plasma insulin response and insulin sensitivity index (ISI) was estimated over a 90 min test period. Further details of the GIT and laboratory techniques have been described [7]. To provide a more definitive assessment of pancreatic function the individual insulin response results were allocated to a "high" or "low" category. Using the normal 15 th percentiles [6] and by reference to similarly derived normal insulin response data [7] these cut-off points were set at $300 \mu \mathrm{U} / \mathrm{ml}$ and $1200 \mu \mathrm{U} / \mathrm{ml}$ for the non-pregnant and pregnant states respectively.

In the pregnant groups $5 \mathrm{ml}$ fasting venous samples were withdrawn and plasma was separated and stored at $-18^{\circ} \mathrm{C}$ for later estimation of progesterone, human placental lactogen, and oestradiol $17-\beta$. 
Results are presented as mean \pm SD values. Student's t test of significance was applied throughout. For lognormal distributions this test was applied using the logarithms of the values.

\section{Results}

\section{Intravenous Glucose Tolerance}

In late pregnancy the mean increment index of the gestational diabetic group was 2.50 (range 1.18 to 2.83). All increment indices had returned to normal at six weeks postpartum (mean 4.20 , range 3.08 to 6.97).

\section{Fasting Plasma Glucose and Fasting Plasma Insulin}

The mean fasting plasma glucose observed during pregnancy at $76 \pm 9 \mathrm{mg} / 100 \mathrm{ml}$ was significantly lower than that observed postpartum at $90 \pm 8 \mathrm{mg}$ / $100 \mathrm{ml}(\mathrm{p}<0.01)$. The mean fasting plasma insulin observed during pregnancy at $13 \pm 3 \mu \mathrm{U} / \mathrm{ml}$ was significantly higher than that observed postpartum at $11 \pm 4 \mu \mathrm{U} / \mathrm{ml}(\mathrm{p}<0.01)$.

\section{Glucose Infusion Test}

The mean plasma glucose levels maintained at infusion in the gestational diabetic group during pregnancy and postpartum are shown in Figure 1. Each level was maintained at around $260-270 \mathrm{mg} / 100 \mathrm{ml}$ over the test period. The overall means of the individual mean plasma glucose levels were $268 \pm 7 \mathrm{mg}$ / $100 \mathrm{ml}$ for the late pregnancy tests and $269 \pm 7 \mathrm{mg}$ / $100 \mathrm{ml}$ for the postpartum tests.

\section{Plasma Insulin Response}

When the incremental plasma insulin values were plotted against time, biphasic plasma insulin response patterns were observed in all subjects. Figure 2 presents the mean incremental plasma insulin responses over $90 \mathrm{~min}$ in each group. The mean first and second phase insulin responses were greater in the pregnant group. In both groups the first insulin response phase had occurred within $5 \mathrm{~min}$. The second insulin response phase continued to rise to maximum mean values at $90 \mathrm{~min}$ in the pregnant group, and at $80 \mathrm{~min}$ in the postpartum group.

\section{Insulin Response Status}

The individual summated 90 -min insulin responses for the gestational diabetic women during pregnancy and postpartum are presented in Figure 3.
Using the cut-off point of $1200 \mu \mathrm{U} / \mathrm{ml}$ for pregnancy, 12 of the 15 gestational diabetic women were identified as "low" insulin responders, while 3 (subjects $13,14,15)$ were "high" insulin responders.

Postpartum 6 of the 12 re-tested women were classified as "low" insulin responders by the nonpregnant cut-off point of $300 \mu \mathrm{U} / \mathrm{ml}$. Three (subjects $13,14,15)$ remained "high" insulin responders, and 3 (subjects $5,10,12$ ) who were classified as "low" insulin responders during pregnancy were found to be "high" insulin responders postpartum.

The three women who were not re-tested postpartum had the fourth lowest, third lowest, and lowest insulin response results in the total pregnant group; indeed, subject 1 was also classified as "low" by the non-pregnant standard.

\section{Insulin Sensitivity Index}

The mean ISI values observed in the diabetic groups are presented in Table 1. These are compared with similarly derived non-pregnant and pregnant values for non-diabetic women [7].

In the pregnant state the mean ISI of the gestational diabetic women was found to be significantly greater than the mean ISI of the normal pregnant group. In the non-pregnant state the mean ISI values in the gestational diabetic group and the control group were similar.

In the gestational diabetic group the ISI was significantly greater postpartum than during pregnancy.

Of the 12 gestational diabetic women tested postpartum the six "low" insulin responders had a significantly higher ISI at $4.12 \pm 1.74$ compared with the six "high" insulin responders at $1.92 \pm 0.62(\mathrm{p}<$ $0.05)$.

\section{Correlation Data Analysis}

Correlation was sought between increment index and the first phase, second phase, and summated 90 -min peripheral plasma insulin responses and also with the insulin sensitivity index. No correlations were significant.

\section{Fasting Plasma Progesterone, Human Placental Lactogen, and Oestradiol 17- $\beta$}

In the pregnant gestational diabetic group the mean fasting plasma values for progesterone, human placental lactogen, and oestradiol $17-\beta$ were respectively $428 \pm 195 \mathrm{nmol} / \mathrm{l}, 81 \pm 14 \mu \mathrm{g} / \mathrm{l}$, and $30.4 \pm$ $5.9 \mu \mathrm{g} / \mathrm{l}$. No correlation was found between the fasting levels of these hormones and increment index, first phase, second phase, and summated 90-min insulin responses or ISI. 


\section{Discussion}

Using a standardised glycaemic stimulus this study provides evidence that gestational diabetes (increment index of the IVGTT $<2.97$ during pregnancy and $>2.97$ six weeks postpartum) may be associated with a relative deficiency in insulin response. Similar observations using single shot intravenous glucose techniques have been made by Spellacy [13] and Yen and co-workers [14]. These data are consistent with the hypothesis that pregnancy related glucose intolerance may be precipitated in women who are unable to achieve adequate insulinogenic compensation. Furthermore, this study contradicts the alternative hypothesis that insulin antagonism per se is the major factor in gestational diabetes. Indeed, the observed biological sensitivity to endogenous insulin was higher during pregnancy in the gestational diabetic group compared with the control group. In the gestational diabetic women who were re-tested postpartum, in the terms of Cerasi and Luft [12], the "low" insulin responders demonstrated greater insulin sensitivity compared with the "high" insulin responders. Similar findings have been reported for non-diabetic subjects with "low" insulin responses in the non-pregnant state [15] and during pregnancy [16]. Those authors believed that increased insulin sensitivity may be a compensatory mechanism in "low" insulin responders. The present study suggests that a similar compensatory mechanism, albeit inadequate, may be present in gestational diabetes.

When comparing the mean biphasic insulin response curves with previously presented nondiabetic data [7] there was no evidence of any major delay in the first or second insulin response phases in the diabetic group during pregnancy or postpartum. Furthermore the mean insulin response curves were uniformly lower in both gestational diabetic groups compared with their control groups. These observations suggest that the lower insulin responses may be related to a shift in glucose-insulin dose-response kinetics. Half the women studied were identified as "low" insulin responders during pregnancy and postpartum. Assuming that a postpartum insulin response represents the basal state, gestational diabetes in these women may have been related to "a selective impairment of $\beta$-cell glucoreceptor sensitivity" [6]. These data are also consistent with previous observations [17] that the "low" insulin response may be associated with a limited capacity for insulinogenic compensation during metabolic stress.

A similar $\beta$-cell defect cannot be postulated for the six women who were "high" insulin responders at the time that they were re-tested postpartum. Indeed, their "high" insulin responses could reflect a delayed return to the non-pregnant baseline. These women did have higher insulin responses during pregnancy, but their compensation was apparently inadequate to achieve normal intravenous glucose tolerance.

Specific factors which mediate the metabolic realignments of pregnancy have not been clearly defined. Progesterone, human placental lactogen, and oestradiol are believed to have not only insulinotrophic but also contra-insulin actions $[18,19,20$, 21]. No correlation was found between any of these hormones and increment index, insulin response or insulin sensitivity. The mean fasting values of these hormones in the gestational diabetic group were not significantly different $(p>0.05)$ from similarly derived mean values in normal pregnant women [7]. These data suggest that none of these hormones has a dominant diabetogenic influence.

The mean fasting plasma glucose levels during pregnancy were similar in the gestational diabetic group to those previously reported for normal pregnant women [7]. This is in agreement with the observations of Sutherland and co-workers [22]. The mean fasting plasma insulin levels were also similar. Compared with the normal non-pregnant data previously reported [7] the gestational diabetic group postpartum had a higher mean fasting plasma glucose level and a lower mean increment index. These differences were significant $(p<0.05)$ and are consistent with the tendency towards an abnormal metabolic state in these women.

Acknowledgements. This study was carried out during the tenure of a British Diabetic Association Research Fellowship by P. M. F.

We are grateful to Professor A. I. Klopper, Department of Obstetrics and Gynaecology, University of Aberdeen, for plasma oestradiol $17-\beta$, progesterone, and human placental lactogen estimations.

We gratefully acknowledge the technical assistance of Miss Fiona MacGregor and the secretarial assistance of Miss Mary Grassick.

\section{References}

1. Gross M (1962) Effect of pregnancy on carbohydrate metabolism. Clin Obstet Gynecol 5: 482-496

2. Kalkhoff RK, Schalch DS, Walker JL, Beck P, Kipnis DM, Daughaday WM (1964) Diabetogenic factors associated with pregnancy. Trans Assoc Am Physicians 77: 270-280

3. Jackson WPU, Van Mieghem W, Keller P (1972) Insulin excess as the initial lesion in diabetes. Lancet I: 1040-1044

4. Spellacy WN, Goetz FC, Greenberg BZ, Elis J (1963) Plasma insulin in normal late pregnancy. N Engl J Med 268: 988-991

5. Freinkel N, Herrera E, Knopp RH, Ruder HJ (1970) Metabolic realignment in late pregnancy. A clue to diabetogenesis. In: Camerini-Dávalos R, Cole JS (eds) Early diabetes. Supplement I to Advances in metabolic disorders. Academic Press, New York, p 205-215 
6. Cerasi E, Luft R, Efendic S (1972) Decreased sensitivity of the pancreatic beta cell to glucose in pre-diabetics and diabetic subjects. A glucose dose-response study. Diabetes 21: 224-234

7. Fisher PM, Sutherland HW, Bewsher PD (1980) Insulin response to glucose infusion in normal human pregnancy. Diabetologia 19: 15-20

8. Kemsley WFF (1951) Body weight at different ages and heights. Ann Eugenics 16: 316-334

9. Hytten FE, Leitch I (1971) The physiology of human pregnancy, 2nd ed. Blackwell, Oxford, p 279

10. Duncan LJP (1956) Intravenous glucose tolerance test. Q J Exp Physiol 41: 85-96

11. Sutherland HW, Stowers JM, Cormack JD, Bewsher PD (1973) Evaluation of chlorpropamide in chemical diabetes diagnosed during pregnancy. Br Med J III: 9-13

12. Cerasi E, Luft R (1967) The plasma insulin response to glucose infusion in healthy subjects and in diabetes mellitus. Acta Endocrinol (Kbh) 55: 278-304

13. Spellacy WN (1971) Plasma insulin, growth hormone and placental lactogen levels in normal and abnormal pregnancies. Acta Endodocrinol [Suppl] (Kbh) 155: 82

14. Yen SSC, Tsai CC, Vela P (1971) Gestational diabetogenesis. Quantitative analyses of glucose-insulin inter-relationship between normal pregnancy and pregnancy with gestational diabetes. Am J Obstet Gynecol 111: 792-800

15. Cerasi E, Wahren J, Luft R, Felig P, Hendler R (1973) The regulation of splanchnic glucose production in subjects with low insulin response - a compensatory mechanism in prediabetics? Eur J Clin Invest 3: 193-200

16. Edstrom K, Cerasi E, Luft R (1974) Insulin response to glucose infusion during pregnancy. A prospective study of high and low insulin responders with normal carbohydrate tolerance. Acta Endocrinol (Kbh) 75: 87-104
17. Cerasi E, Luft R (1973) Pathogenesis of genetic diabetes mellitus: Further development of a hypothesis. Mt Sinai J Med NY 40: 334-349

18. Grumbach MM, Kaplan SL, Sciarra JJ, Burr IM (1968) Chorionic growth-hormone-prolactin (CGP): Secretion, disposition, biological activity in man: postulated function as "growth hormone" of second half of pregnancy. Ann NY Acad Sci 148: 501-531

19. Beck P, Daughaday WH (1967) Human placental lactogen: Studies of its acute metabolic effect and disposition in normal man. J Clin Invest 46: 103-110

20. Costrini NV, Kalkhoff RK (1971) Relative effects of pregnancy. Estradiol and progesterone on plasma insulin and pancreatic islet insulin secretion. J Clin Invest 50: 992-999

21. Oakley NW, Monier D, Wynn V (1973) Diurnal variation in oral glucose tolerance: Insulin and growth hormone changes with special reference to women taking oral contraceptives. Diabetologia 9: 235-238

22. Sutherland HW, Fisher PM, Stowers JM (1975) Evaluation of maternal carbohydrate metabolism by the intravenous glucose tolerance test. In: Camerini-Dávalos RA, Cole HS (eds) Early diabetes in early life. Proceedings of the Third International Symposium on Early Diabetes, Funchal. Academic Press, New York, p 365-370

Received: February 19, 1979, and in revised form: February 1, 1980

Peter M. Fisher, M. D., M. R. C. O. G. Department of Obstetrics and Gynaecology University of Aberdeen

Foresterhill

Aberdeen, Scotland 